\title{
Linhagens de feijão do cruzamento 'Ouro Negro' x 'Pérola' com características agronômicas favoráveis
}

\author{
Carlos Lásaro Pereira de Melo(1), José Eustáquio de Souza Carneiro(2), Pedro Crescêncio Souza Carneiro(3), \\ Cosme Damião $\mathrm{Cruz}^{(3)}$, Everaldo Gonçalves de $\operatorname{Barros}^{(3)}$ e Maurílio Alves Moreira ${ }^{(1)}$
}

\begin{abstract}
(1)Embrapa Agropecuária Oeste, Caixa Postal 661, CEP 79804-970 Dourados, MS. E-mail: lasaro@cpao.embrapa.br (2)Universidade Federal de Viçosa (UFV), Centro de Ciências Agrárias, Dep. de Fitotecnia, Av. P. H. Rolfs s/no, CEP 36570-000 Viçosa, MG. E-mail: jesc@ufv.br (3)UFV, Centro de Ciências Biológicas e da Saúde, Dep. de Biologia Geral. E-mail: carneiro@ufv.br, cdcruz@ufv.br, ebarros@ufv.br (4)UFV, Instituto de Biotecnologia Aplicada à Agropecuária, Lab. de Genética Molecular de Plantas. E-mail: moreira@ufv.br
\end{abstract}

Resumo - O objetivo desse trabalho foi avaliar e caracterizar, em casa de vegetação e campo, linhagens do cruzamento entre as cultivares Ouro Negro e Pérola, quanto à reação às principais raças de Colletotrichum lindemuthianum e Uromyces appendiculatus. Quatrocentas progênies $\mathrm{F}_{7: 8}$, de 40 famílias $\mathrm{F}_{3: 7}$ previamente selecionadas na população 'Ouro Negro' x 'Pérola', foram pulverizadas com uma suspensão contendo a raça 89 de C. lindemuthianum. Linhagens resistentes à raça 89 receberam inóculo com as raças 73 e 81 de C. lindemuthianum e com mistura de seis raças de $U$. appendiculatus. Nas avaliações em campo, realizadas em Viçosa e Coimbra, MG, um látice quadrado triplo 9x9 foi utilizado e foram avaliados produtividade de grãos, severidade de manchaangular e aspecto do grão. Foram identificadas 42 linhagens resistentes às raças de C. lindemuthianum e U. appendiculatus. Foram selecionadas dez linhagens de grãos tipo 'Carioca', com produtividade igual à da cultivar Pérola e resistentes à antracnose, ferrugem e mancha-angular.

Termos para indexação: Phaseolus vulgaris, melhoramento do feijoeiro, resistência a doenças.

\section{Lines of common bean originating from the cross 'Ouro Negro' $x$ 'Pérola' comprising favorable agronomic characteristics}

\begin{abstract}
The objective of this work was to obtain high yielding common bean lines with "Carioca" type grains, resistant to anthracnose, rust and angular leaf spot. Colletotrichum lindemuthianum race 89 was artificially inoculated in $400 \mathrm{~F}_{7: 8}$ progenies originated from $40 \mathrm{~F}_{3: 7}$ families previously selected in the population 'Ouro Negro' x 'Pérola'. Lines resistant to race 89 were further inoculated with C. lindemuthianum races 73 and 81 and a mixture of six Uromyces appendiculatus races. Field evaluations were performed in Viçosa and Coimbra, MG, Brazil, using a triple 9x9 lattice design and productivity of grains, severity of angular leaf spot and grain aspect were evaluated. Forty two lines resistant to $C$. lindemuthianum and $U$. appendiculatus were identified. Ten lines comprising "Carioca" type grains, as productive as commercial cultivar Pérola and resistant to the anthracnose, rust and angular leaf spot were selected.
\end{abstract}

Index terms: Phaseolus vulgaris, common bean breeding, disease resistance.

\section{Introdução}

O Brasil é o maior produtor e consumidor mundial de feijão-comum (Phaseolus vulgaris L.). A área cultivada é de aproximadamente quatro milhões de hectares e a produção atinge cerca de três milhões de toneladas (FAO, 2003). Contudo, o rendimento médio do feijão, no Brasil, é baixo, cerca de $779 \mathrm{~kg} \mathrm{ha}^{-1}$ (Conab, 2005). Isto se deve, em parte, ao fato de o feijoeiro ser suscetível a vários organismos fitopatogênicos, responsáveis por perdas significativas nas lavouras, chegando a inviabilizar a cultura em determinadas regiões e épocas de plantio.
Entre as doenças da parte aérea do feijoeiro destacamse a antracnose, causada por Colletotrichum lindemuthianum, a ferrugem, causada por Uromyces appendiculatus, e a mancha-angular, incitada por Phaeoisariopsis griseola. Diversas medidas têm sido empregadas pelos agricultores no controle das doenças do feijoeiro. Entretanto, o uso de cultivares resistentes merece atenção, principalmente, por não onerar o custo de produção e por reduzir os impactos negativos, causados ao homem e ao meio ambiente.

Entre as cultivares de feijão recomendadas para cultivo no Brasil, destacam-se as do grupo Carioca - 
feijões com grãos de cor creme e rajas de cor marrom. Muitas possuem excelentes qualidades, mas não apresentam adequada resistência aos patógenos, constituindo-se em alvo para os programas de melhoramento. Esse é o caso da cultivar Pérola, uma das mais cultivadas no Brasil. Esta cultivar é referência quanto à produtividade e qualidade de grãos, porém é suscetível às principais raças de $C$. lindemuthianum e $U$. appendiculatus predominantes nas regiões produtoras de Minas Gerais (Lanza et al., 1997; Faleiro et al., 1999). A cultivar Ouro Negro, do grupo preto, desde seu lançamento em 1991 (Araújo et al., 1991), tem-se destacado como resistente às raças 73, 81 e 89 de C. lindemuthianum e a várias raças de U. appendiculatus (Faleiro et al., 2001).

O objetivo deste trabalho foi avaliar e caracterizar, em condições de casa de vegetação e de campo, linhagens do cruzamento entre as cultivares Ouro Negro e Pérola quanto à reação às principais raças de C. lindemuthianum e U. appendiculatus.

\section{Material e Métodos}

Quarenta famílias $F_{3: 7}$ da população 'Ouro Negro' x 'Pérola', previamente avaliadas e selecionadas por Santos (2001), foram cultivadas em campo na safra de inverno de 2003, no campo experimental de Coimbra, MG, pertencente à Universidade Federal de Viçosa. De cada família, foram tomadas dez plantas com grãos do tipo Carioca, originando progênies $F_{7: 8}$.

Doze sementes, de cada uma das 400 progênies e de cada um dos genitores, 'Ouro Negro' e 'Pérola', foram semeadas em bandejas de plástico em casa de vegetação, contendo uma mistura de solo e esterco curtido, na proporção de 4:1, adubada com o formulado de NPK 4-14-8, na dose de $5 \mathrm{~kg} \mathrm{~m}^{-3}$ do substrato, para a avaliação da reação à raça 89 de C. lindemuthianum. As plantas foram mantidas em casa de vegetação até o momento da inoculação.

No preparo do inóculo de C. lindemuthianum, adotou-se o método descrito por Pio-Ribeiro \& Chaves (1975) com adaptações (redução na concentração de $2 \times 10^{6}$ para $1,2 \times 10^{6}$ conídios $\mathrm{mL}^{-1} \mathrm{e}$ substituição do meio extrato de vagem ágar pelo meio ágar-água). O inóculo de cada raça foi produzido em tubos de ensaio, contendo vagens esterilizadas e parcialmente imersas em meio ágar-água. Os tubos contendo o inóculo foram incubados por dez dias em temperatura entre 23 e $24^{\circ} \mathrm{C}$, para produção dos conídios utilizados na aspersão.

Aos seis a dez dias depois a semeadura, uma suspensão com $1,2 \times 10^{6}$ conídios $\mathrm{mL}^{-1}$ foi aspergida em ambas as superfícies das folhas primárias, com o auxílio de um atomizador De Vilbiss no 15 acionado por um compressor elétrico. Após a aspersão e rápida secagem ao ar, as plantas foram incubadas, por um período de seis a sete dias, em câmara de nevoeiro $\left(20 \pm 1^{\circ} \mathrm{C}\right.$ e umidade relativa acima de 95\%), sob fotoperíodo de 12 horas.

Depois da incubação, realizou-se a avaliação dos sintomas da antracnose, com base na escala de notas de 1 a 9, descrita por Pastor-Corrales (1992). As plantas com graus de reação 1 a 3 foram consideradas resistentes e, as com graus de 4 a 9 foram consideradas suscetíveis.

Linhagens resistentes à raça 89 foram avaliadas quanto à reação as raças 73 e 81 de $C$. lindemuthianum. Essas raças de $C$. lindemuthianum foram escolhidas por serem freqüentes no Brasil (Rava et al., 1994; Alzate-Marin \& Sartorato, 2004).

As mesmas linhagens também foram avaliadas quanto à reação às misturas das raças $15,35,45,49,50$ e 59 de U. appendiculatus, às quais 'Ouro Negro' é resistente (Ragagnin et al., 2003). O preparo do solo, a adubação e a condução das plantas até o momento da aspersão dos inóculos foram semelhantes aos do ensaio com a raça 89 de $C$. lindemuthianum.

Os uredósporos, na concentração de $2,0 \times 10^{4}$ esporos $\mathrm{mL}^{-1}$, foram suspensos em água destilada contendo $0,05 \%$ de Tween 20 , e foram pulverizados em ambas as superfícies de folhas primárias com, aproximadamente, dois terços do seu desenvolvimento, com o auxílio de um atomizador De Vilbiss no 15, acionado por um compressor elétrico. Depois da pulverização e rápida secagem ao ar, as plantas foram transferidas para câmara de nevoeiro ( $20 \pm 1^{\circ} \mathrm{C}$ e umidade relativa acima de $95 \%$ ), onde permaneceram por 48 horas, sob fotoperíodo de 12 horas. Posteriormente, as plantas foram novamente transferidas para casa de vegetação $\left(20 \pm 5^{\circ} \mathrm{C}\right)$, onde permaneceram até serem avaliadas, cerca de 15 dias após a pulverização.

$\mathrm{Na}$ avaliação dos sintomas, foram consideradas seis classes de reação, segundo escala proposta por Stavely et al. (1983). As plantas com graus de severidade entre 1 e 3 foram consideradas resistentes e as com grau entre 4 e 9 , suscetíveis. 
As linhagens que se mostraram resistentes à raça 89 de $C$. lindemuthianum, testadas em casa de vegetação, foram avaliadas em campo, na safra da seca de 2004, em Viçosa e Coimbra, Minas Gerais. Um total de 81 tratamentos (75 linhagens e 6 testemunhas) foram avaliados, utilizando-se o delineamento experimental em látice quadrado, com três repetições, sendo as parcelas constituídas de duas fileiras de $2 \mathrm{~m}$ cada, espaçadas em $0,5 \mathrm{~m}$. Como padrões, foram utilizados os dois genitores ('Ouro Negro' e 'Pérola') e as cultivares Talismã, VC4, Vi 4899 e Rudá piramidado (Rudá "R"), que apresenta genes de resistência à antracnose (Co-4, Co-6, Co-10), mancha-angular (Phg-1) e ferrugem (Ur-ON) (Ragagnin et al., 2005). Foram avaliados a produtividade de grãos, o aspecto dos grãos e a severidade de manchaangular.

Na avaliação do aspecto do grão, utilizou-se uma escala de notas de 1 a 5 (Marques Júnior et al., 1997). A nota 5 foi concedida aos materiais, que apresentaram grãos fora do padrão Carioca. Para avaliar a severidade de mancha-angular, adotou-se escala diagramática, com notas variando de 1 (plantas com ausência de sintoma da doença) a 9 (plantas totalmente infectadas pelo patógeno) (Centro Internacional de Agricultura Tropical, 1987).

Na análise de variância do caráter produtividade de grãos, adotou-se o seguinte modelo estatístico: $\mathrm{Y}_{\mathrm{ijk}}=\mu+\mathrm{g}_{\mathrm{i}}+\mathrm{r}_{\mathrm{j}}+\mathrm{b}_{\mathrm{k}(\mathrm{j})}+\varepsilon_{\mathrm{ijk}}$, em que $\mathrm{Y}_{\mathrm{ijk}}$ é a observação referente ao i-ésimo tratamento na j-ésima repetição e k-ésimo bloco; $\mu$ é a constante inerente a todas as observações; gi é o efeito do i-ésimo tratamento; ( $\mathrm{i}=1$, $2, \ldots, g+t)$, sendo g o número de linhagens (75) e t o número de testemunhas (6); $\mathrm{r}_{\mathrm{j}}$ é o efeito da j-ésima repetição $(\mathrm{j}=1,2,3)$; $\mathrm{b}_{\mathrm{k}(\mathrm{j})}$ é o efeito do k-ésimo bloco dentro da j-ésima repetição $(\mathrm{k}=1,2, \ldots 9)$; e $\varepsilon_{\mathrm{ijk}}$ é o erro aleatório, $\varepsilon_{\mathrm{ijk}} \sim \operatorname{NID}\left(0, \sigma^{2}\right)$.

Análises de variância de outras características aspecto do grão e severidade de mancha-angular - foram realizadas, adotando-se o modelo estatístico de blocos ao acaso, pelo fato de estes caracteres não serem influenciados pela heterogeneidade do solo. Dessa forma, utilizou-se o modelo estatístico: $\mathrm{Y}_{\mathrm{ij}}=\mu+\mathrm{g}_{\mathrm{i}}+\mathrm{b}_{\mathrm{j}}+\varepsilon_{\mathrm{ij}}$, em que $Y_{\mathrm{ij}}$ é a observação referente ao i-ésimo tratamento no j-ésimo bloco; $\mu$ é a constante inerente a todas as observações; $g_{i}$ é o efeito do i-ésimo tratamento ( $i=1,2, \ldots, g+t)$, sendo g o número de linhagens (75) e $t o$ número de testemunhas (6); $b_{j}$ é o efeito do j-ésimo bloco $\left(\mathrm{j}=1,2\right.$, 3); e $\varepsilon_{\mathrm{ij}}$ é o erro aleatório, $\varepsilon_{\mathrm{ij}} \sim \operatorname{NID}\left(0, \sigma^{2}\right)$.
Nas análises estatísticas, utilizou-se o programa Genes (Cruz, 2001). Os tratamentos foram submetidos ao teste de Dunnett (Vieira \& Hoffmann, 1989), para comparação das médias de todas as características avaliadas com as testemunhas.

\section{Resultados e Discussão}

Do total de 400 progênies com inoculação da raça 89 de C. lindemuthianum, 75 mostraram-se resistentes, sendo que 68 destas, com grãos de boa aceitação comercial, foram selecionadas para avaliação de reação às raças 73 e 81 de $C$. lindemuthianum e da mistura de raças de $U$. appendiculatus (15, 35, 45, 49, 50 e 59). Estas 68 linhagens correspondem a 15 famílias $F_{3: 7}$ das 40 , inicialmente, avaliadas.

Das 68 progênies resistentes à raça 89, 66 foram resistentes à raça 81 e 61 resistentes à raça 73 , evidenciando elevada coincidência dos dados de reação às três raças. Este resultado corrobora os obtidos por Alzate-Marin et al. (2003) e Faleiro et al. (2003), uma vez que o gene $\mathrm{Co}-10$ confere resistência a estas três raças de C. lindemuthianum e estão presentes no mesmo grupo de ligação, com o gene $U r$-ON que confere resistência a várias raças de $U$. appendiculatus.

Posteriormente, foi avaliada a reação das 68 linhagens resistentes à raça 89 de $C$. lindemuthianum, a uma mistura de raças de $U$. appendiculatus. Do total de 68 linhagens selecionadas para antracnose, $62 \%$ foram resistentes à ferrugem.

Considerando somente os resultados da caracterização fenotípica, obtidos em casa de vegetação, foram selecionadas 42 linhagens resistentes à antracnose (raças 73, 81 e 89) e à ferrugem, com os genes de resistência Co-10 e Ur-ON oriundos do genitor 'Ouro Negro', e bom aspecto de grão Carioca.

Em campo, 75 linhagens do cruzamento 'Pérola' x 'Ouro Negro', que se mostraram resistentes à raça 89 de C. lindemuthianum, além de seis testemunhas (padrões comerciais), foram avaliadas quanto à produtividade de grãos, aspecto dos grãos e severidade de mancha-angular. Observou-se efeito significativo quanto à fonte de variação linhagens, tanto em análises individuais como na conjunta, para todos os caracteres avaliados.

A média de produtividade de grãos das linhagens foi de $3.633 \mathrm{~kg} \mathrm{ha}^{-1}$, resultado esse esperado, uma vez que 
as cultivares Pérola e Ouro Negro, envolvidas no cruzamento, são as de maior potencial de produção em seus respectivos grupos comerciais. Porém, a cultivar Ouro Negro apresentou uma das menores produtividades (2.907 $\left.\mathrm{kg} \mathrm{ha}^{-1}\right)$. Este fato não é comum nos ensaios em que a cultivar Ouro Negro participa. Contudo, nesta safra, esta cultivar apresentou uma das maiores notas de severidade de mancha-angular, o que provavelmente contribuiu para esse reduzido rendimento.

Na análise das médias das 75 linhagens, observou-se ampla variabilidade quanto aos caracteres produtividade de grãos, aspecto dos grãos e severidade à manchaangular. Quanto à produtividade de grãos, 23 linhagens apresentaram comportamento similar à 'Pérola' (3.467 kg ha-1) e à 'Rudá' "R" (3.746 kg ha-1). A distribuição de freqüência também ilustra a existência de variabilidade entre as linhagens avaliadas quanto à produtividade de grãos. Esta característica apresentou distribuição próxima à normal, evidenciando a natureza quantitativa deste caráter. A maioria das linhagens foi superior à cultivar Ouro Negro, e mais da metade apresentou produtividade superior à 'Pérola' (Figura 1).

Quanto ao aspecto dos grãos, os genitores 'Pérola' e 'Ouro Negro' apresentaram notas 1,5 e 5, respectivamente. As notas, obtidas pelas linhagens, variaram de 1,3 a 3,7, sendo a menor nota atribuída às linhagens com melhor aspecto de grão. Acultivar Talismã, considerada como padrão para esta característica, obteve nota 1,8. Já a 'Rudá' "R", apesar de ter apresentado boa produtividade, possui coloração do grão inferior à cultivar Pérola, com nota 2,3 (Tabela 1). Trinta e três linhagens apresentaram notas, quanto ao aspecto de grão, menores que 2,2, equiparando-se estatisticamente à cultivar Pérola, sendo, portanto promissoras do ponto de vista de aspecto comercial dos grãos (Figura 2). Observa-se maior concentração de linhagens com notas inferiores, ou seja, com bom aspecto de grão.

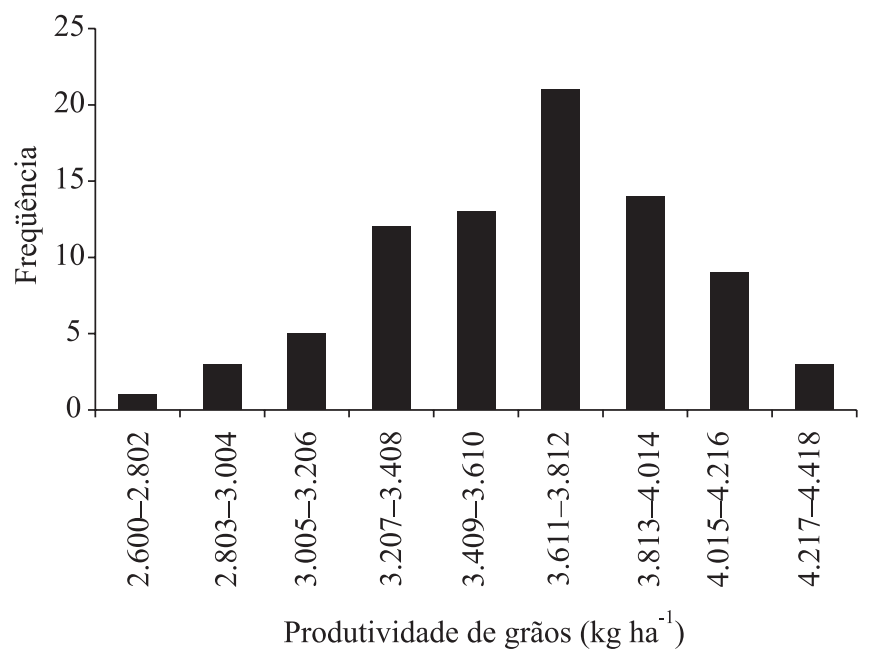

Figura 1. Distribuição de freqüência da produtividade de grãos, obtida na avaliação de 75 linhagens de feijão "Carioca” e seis testemunhas, em Viçosa e Coimbra, MG, na safra da seca de 2004.

Tabela 1. Produtividade de grãos, aspecto dos grãos (AG) e severidade de mancha-angular (MA) das dez melhores linhagens do cruzamento 'Ouro Negro' x 'Pérola' em Viçosa e Coimbra, MG, na safra da seca de 2004(1).

\begin{tabular}{|c|c|c|c|c|c|}
\hline \multirow[t]{2}{*}{ Linhagens } & \multicolumn{3}{|c|}{ Produtividade de grãos $\left(\mathrm{kg} \mathrm{ha}^{-1}\right)$} & \multirow[t]{2}{*}{$\mathrm{AG}$} & \multirow[t]{2}{*}{ MA } \\
\hline & Viçosa & Coimbra & Conjunta & & \\
\hline OP-196 & 5.149 & $3.484 \mathrm{abc}$ & $4.317 \mathrm{a}$ & $2,3 a$ & $3,7 \mathrm{ab}$ \\
\hline OP-145 & 4.616 & $4.016 \mathrm{ab}$ & $4.316 \mathrm{a}$ & $1,3 b$ & $4,0 \mathrm{ab}$ \\
\hline OP-60 & 4.437 & $4.011 \mathrm{ab}$ & $4.224 a$ & $1,8 \mathrm{ab}$ & $4,0 \mathrm{ab}$ \\
\hline OP-195 & 4.542 & $3.801 \mathrm{abc}$ & $4.172 \mathrm{a}$ & $2,2 \mathrm{a}$ & $4,0 \mathrm{ab}$ \\
\hline OP-58 & 4.504 & $3.661 \mathrm{abc}$ & $4.083 \mathrm{ab}$ & $1,5 \mathrm{~b}$ & $2,7 \mathrm{ab}$ \\
\hline OP-192 & 4.178 & $3.981 \mathrm{ab}$ & $4.080 \mathrm{ab}$ & $2,0 \mathrm{ab}$ & $4,0 \mathrm{ab}$ \\
\hline OP-186 & $4.061 \mathrm{a}$ & $4.096 \mathrm{ab}$ & $4.079 \mathrm{ab}$ & $2,3 \mathrm{a}$ & $3,0 \mathrm{ab}$ \\
\hline OP-188 & 4.503 & $3.625 \mathrm{abc}$ & $4.064 \mathrm{ab}$ & $2,2 \mathrm{a}$ & $3,7 \mathrm{ab}$ \\
\hline OP-166 & 4.449 & $3.659 \mathrm{abc}$ & $4.054 \mathrm{ab}$ & $2,2 \mathrm{a}$ & $4,0 \mathrm{ab}$ \\
\hline OP-29 & 4.176 & $3.867 \mathrm{abc}$ & $4.022 \mathrm{ab}$ & $2,3 a$ & $3,3 \mathrm{ab}$ \\
\hline Rudá "R" & $3.750 \mathrm{a}$ & $3.741 \mathrm{a}$ & $3.746 a$ & $2,3 a$ & $3,3 a$ \\
\hline Pérola ${ }^{(2)}$ & $3.702 b$ & $3.231 \mathrm{~b}$ & $3.467 \mathrm{~b}$ & $1,5 b$ & $4,0 \mathrm{~b}$ \\
\hline Ouro Negro ${ }^{(3)}$ & $2.891 \mathrm{c}$ & $2.923 \mathrm{c}$ & $2.907 \mathrm{c}$ & $5,0 \mathrm{c}$ & $5,7 \mathrm{c}$ \\
\hline Média & 4.461 & 3.820 & 4.141 & 2,0 & 3,6 \\
\hline $\mathrm{CV}(\%)$ & 9,74 & 12,33 & 9,18 & 11,85 & 12,73 \\
\hline
\end{tabular}

(1)Médias seguidas pelas letras a, b e c não diferem das testemunhas Rudá "R", Pérola e Ouro Negro, respectivamente, pelo teste de Dunnett, a 5\% de probabilidade. ${ }^{(2)}$ Genitor, padrão comercial. ${ }^{(3)}$ Genitor. 


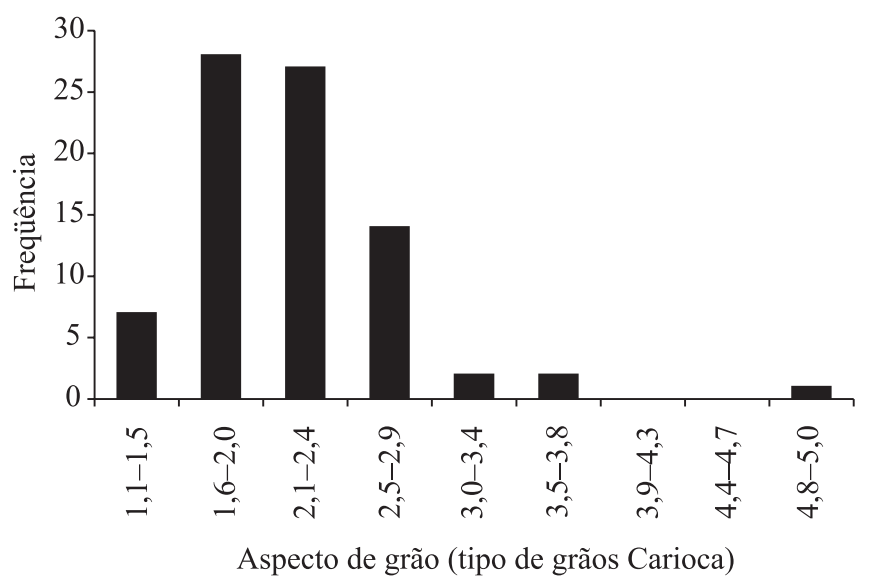

Figura 2. Distribuição de freqüência do aspecto de grão, obtida na avaliação de 75 linhagens de feijão "Carioca” e seis testemunhas, em Viçosa e Coimbra, MG, na safra da seca de 2004.

Assim, infere-se que a seleção, no que tange ao aspecto de grão, realizada durante o avanço das gerações, na etapa anterior a este trabalho, foi eficiente para aumentar a freqüência de genótipos favoráveis com relação a esta característica.

Quanto às doenças, observou-se ocorrência generalizada de mancha-angular em toda a área experimental nessa época de plantio. Conforme Paula Júnior \& Zambolim (1998), o cultivo de feijão na safra da seca proporciona condições favoráveis à ocorrência dessa doença.

Os graus de severidade de mancha-angular variaram de 2,7 a 6,0. A cultivar Ouro Negro, com grau 5,7, foi uma das mais suscetíveis, enquanto as cultivares Pérola, Vi 4899 e Rudá "R" comportaram-se como sendo moderadamente resistentes, com grau menor ou igual a 4. Sessenta e sete linhagens equipararam-se à cultivar Pérola quanto à resistência à mancha-angular, enquanto seis foram estatisticamente inferiores, com graus variando de 2,7 a 3,3.

A cultivar Ouro Negro possui resistência a, pelo menos, duas raças de P. griseola (Corrêa, 1999; Faleiro et al., 2003). Entretanto, conforme relatado, a 'Ouro Negro', em condições de campo, foi uma das mais suscetíveis à mancha-angular. Tal fato indica a presença de outras raças do patógeno no local de plantio, demonstrando ampla variabilidade patogênica do fungo P. griseola (Nietsche et al., 2001; Sartorato \& Alzate-Marin, 2004).

Pela distribuição de freqüência da severidade à mancha-angular (Figura 3), observa-se a ocorrência de

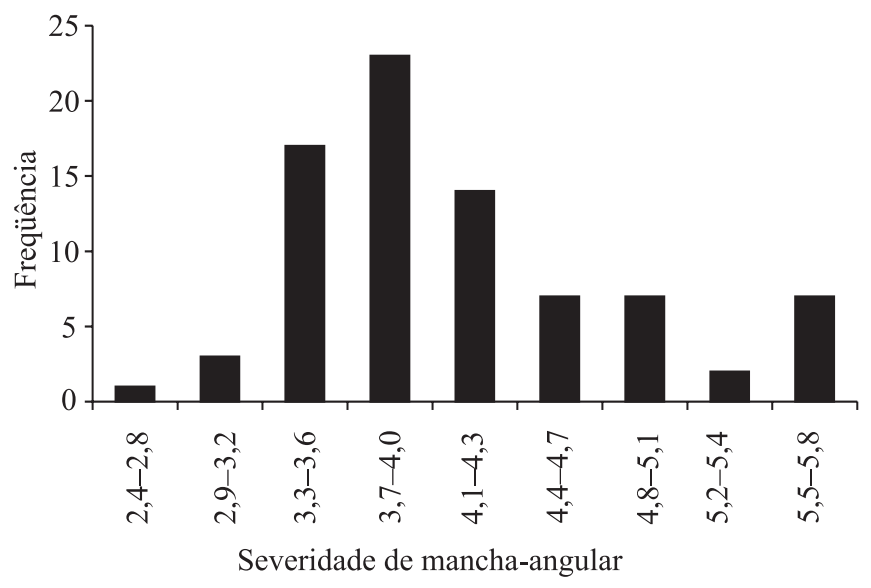

Figura 3. Distribuição de freqüência para severidade de mancha-angular, obtida na avaliação de 75 linhagens de feijão "Carioca" e seis testemunhas, em Viçosa e Coimbra, MG, na safra da seca de 2004.

linhagens com graus de severidade abaixo daqueles dos genitores, o que demonstra o potencial dessas linhagens, também, no que se refere à resistência à manchaangular.

Portanto, em casa de vegetação e avaliações em campo, foi possível selecionar dez linhagens de grãos tipo Carioca resistentes à antracnose (raças 73, 81 e 89), ferrugem (mistura das raças 15, 35, 45, 49, 50 e 59), moderadamente resistentes à mancha-angular e com produtividade de grãos igual à cultivar Pérola (Tabela 1). Algumas dessas linhagens foram incluídas nos ensaios de valor de cultivo e uso (VCU), ciclo 2005/2006, visando futuras recomendações para o Estado de Minas Gerais.

\section{Conclusões}

1. Quarenta e duas linhagens de feijão do cruzamento 'Ouro Negro' x 'Pérola', com grãos tipo Carioca, apresentam resistência a Colletotrichum lindemuthianum (raças 73, 81 e 89) e a Uromyces appendiculatus (mistura das raças 15, 35, 45, 49, 50 e 59).

2. Dez linhagens resistentes à antracnose, ferrugem e mancha-angular apresentam a mesma produtividade e qualidade de grão da cultivar Pérola.

\section{Agradecimentos}

À Fapemig e ao CNPq, pelo financiamento do projeto de pesquisa e concessão de bolsa. 


\section{Referências}

ALZATE-MARIN, A.L.; COSTA, M.R.; ARRUDA, K.M.; BARROS, E.G. de; MOREIRA, M.A. Characterization of the anthracnose resistance gene present in Ouro Negro (Honduras 35) common bean cultivar. Euphytica, v.133, p.165-169, 2003.

ALZATE-MARIN, A.L; SARTORATO, A. Analysis of the pathogenic variability of Colletotrichum lindemuthianum in Brazil. Annual Report of the Bean Improvement Cooperative, v.7, p.241242, 2004.

ARAÚJO, G.A. de A.; VIEIRA, C.; SOUZA FILHO, B.F. de. “Ouro Negro” nova variedade de feijão-preto para os estados de Minas Gerais e Rio de Janeiro. Belo Horizonte: Epamig, 1991. 2p. (Boletim técnico, 1).

CENTRO INTERNACIONAL DE AGRICULTURA TROPICAL. Sistema estándar para la evaluación de germoplasma de frijol. Cali, 1987. 56p.

CONAB. $4^{\circ}$ levantamento da safra 2004/2005. Disponível em: $<$ http://www.conab.gov.br/safra/4levantamentoplantio>. Acesso em: jun. 2005.

CORRÊA, R.X. Genes de resistência a doenças do feijoeiro: identificação de marcadores, organização e identificação de análogos. 1999. 116p. Tese (Doutorado) - Universidade Federal de Viçosa, Viçosa.

CRUZ, C.D. GENES: versão Windows. Viçosa: UFV, 2001. 642p. FALEIRO, F.G.; NIETSCHE, S.; RAGAGNIN, V.A.; BORÉM, A.; MOREIRA, M.A.; BARROS, E.G. Resistência de cultivares de feijoeiro-comum à ferrugem e à mancha angular em condições de casa de vegetação. Fitopatologia Brasileira, v.26, p.86-89, 2001.

FALEIRO, F.G.; RAGAGNIN, V.A.; SCHUSTER, I.; CORRÊA, R.X.; GOOD-GOD, P.I.; BROMMONSHENKEL, S.H.; MOREIRA, M.A.; BARROS, E.G. Mapeamento de genes de resistência do feijoeiro à ferrugem, antracnose e mancha-angular usando marcadores RAPD. Fitopatologia Brasileira, v.28, p.5966, 2003.

FALEIRO, F.G.; VINHADELLI, W.S.; RAGAGNIN, V.A.; PAULA JÚNIOR, T.J.; MOREIRA, M.A.; BARROS, E.G. Resistência de variedades de fejoeiro-comum a quatro raças de Uromyces appendiculatus. Revista Ceres, v.46, p.11-18, 1999.

FAO. Agriculture data. Disponível em: <http:// www.faostat.fao.org/faostat/2003>. Acesso em: nov. 2003.

LANZA, M.A.; PAULA JÚNIOR, T.J.; VINHADELLI, W.S.; MORANDI, M.A.B.; BARROS, E.G.; MOREIRA, M.A. Resistência à antracnose em cultivares de feijoeiro-comum recomendadas para Minas Gerais. Fitopatologia Brasileira, v.22, p.560-562, 1997.
MARQUES JÚNIOR, O.G.; RAMALHO, M.A.P.; FERREIRA, D.F.; SANTOS, J.B. Viabilidade do emprego de notas na avaliação de alguns caracteres do fejoeiro (Phaseolus vulgaris L.). Revista Ceres, v.44, p.411-420, 1997.

NIETSCHE, S.; BORÉM, A.; CARVALHO, G.A.; PAULA JÚNIOR, T.J.; FORTES-FERREIRA, C.; BARROS, E.G.; MOREIRA, M.A. Genetic diversity of Phaeoisariopsis griseola in the State of Minas Gerais, Brazil. Euphytica, v.117, p.77-84, 2001.

PASTOR-CORRALES, M.A. Recomendaciones y acuerdos del primer taller de antracnosis en América Latina. In: PASTORCORRALES, M.A. (Ed.). La antracnosis del frijol común, Phaseolus vulgaris, en América Latina. Cali: CIAT, 1992. p.240250. (Doc. de trabajo, 113).

PAULA JÚNIOR, T.J.; ZAMBOLIM, L. Doenças. In: VIEIRA, C.; PAULA JÚNIOR, T.J.; BORÉM, A. (Ed.). Feijão: aspectos gerais e cultura no Estado de Minas. Viçosa: UFV, 1998. p.375-433.

PIO-RIBEIRO, G.; CHAVES, G.M. Raças fisiológicas de Colletotrichum lindemuthianum (Sacc. et Magn.) Scrib. que ocorrem em alguns municípios de Minas Gerais, Espírito Santo e Rio de Janeiro. Experientiae, v.19, p.95-118, 1975.

RAGAGNIN, V.A.; ALZATE-MARIN, A.L.; SOUZA, T.L.P.O.; ARRUDA, K.M.; MOREIRA, M.A.; BARROS, E.G. Avaliação da resistência de isolinhas de feijoeiro a diferentes patótipos de Colletotrichum lindemuthianum, Uromyces appendiculatus e Phaeoisariopsis griseola. Fitopatologia Brasileira, v.28, p.591596, 2003.

RAGAGNIN, V.A.; ALZATE-MARIN, A.L.; SOUZA, T.L.P.O.; SANGLARD, D.A.; MOREIRA, M.A.; BARROS, E.G. Use of molecular markers to pyramiding multiple genes for resistance to rust, anthracnose and angular leaf spot in the common bean. Annual Report of the Bean Improvement Cooperative, v.48, p.94-95, 2005.

RAVA, C.A.; PURCHIO, A.; SARTORATO, A. Caracterização de patótipos de Colletotrichum lindemuthianum que ocorrem em algumas regiões produtoras de feijoeiro comum. Fitopatologia Brasileira, v.19, p.167-172, 1994.

SANTOS, V. da S. Implicações da seleção precoce para tipo de grão no melhoramento genético do feijoeiro comum. 2001. 57p. Dissertação (Mestrado) - Universidade Federal de Lavras, Lavras.

SARTORATO, A.; ALZATE-MARIN, A.L. Analysis of the pathogenic variability of Phaeoisariopsis griseola in Brazil. Annual Report of the Bean Improvement Cooperative, v.47, p.235-236, 2004.

STAVELY, J.R.; FREYTAG, G.F.; STEADMAN, J.R.; SCHWARTZ, H.F. The 1983 bean rust workshop. Annual Report of the Bean Improvement Cooperative, v.26, p.4-6, 1983.

VIEIRA, S.; HOFFMANN, R. Estatística experimental. São Paulo: Atlas, 1989. 179p. 